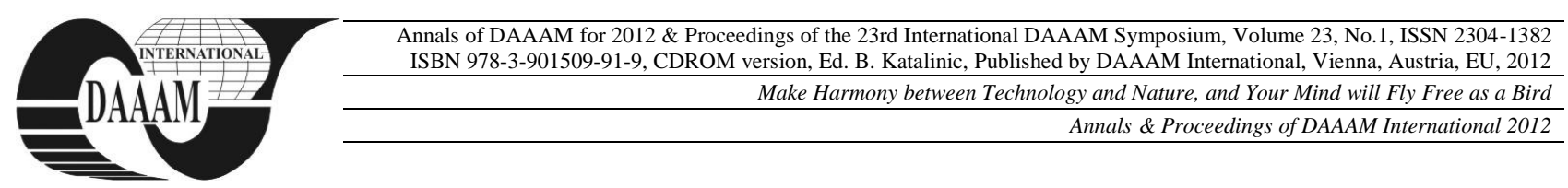

\title{
SERVICE ROBOT APPLICATIONS FOR LOGISTICS
}

\author{
KARABEGOVIC, I[sak] \& PASAGIC SKRINJAR, J[asmina]
}

\begin{abstract}
Logistic service robots are automated systems that can be easily adapted to various environments. Thus, the mobile robot variants can be found even in non-productive fields such as offices, hospitals, postal systems and postal automation services. The efficiency of logistic processes is reflected also through the time of realization. The example is a simple one: food availability logistics in the stores. The United States are currently importing more than 100,000 containers daily of contents that have to be processed, distributed and made available to the users. Robotics as technology provides opportunity to improve the logistic processes in term of smaller defects and shorter times for the realization of certain logistic processes. The paper has given a presentation of the increasing trend of using robotics in logistics. In the future, the application of service robots for logistics is unlimited, in that they will be implemented both in offices, houses, hospitals, post-offices, factories, ports, airports, cities for urban passenger transport, warehouses, etc. The drawbacks that will have to be dealt with in the future include robot's recognition of the environment and system improvement in order to avoid downtimes.

Keywords: logistics, robot, service robots, application
\end{abstract}

\section{INTRODUCTION}

Logistic service robots are robots that transport goods and humans in general. Logistic service robots are automated systems that can be easily adapted to various environments. Thus, mobile robot variants can be found also in non-productive fields such as offices, hospitals, post-offices and postal automation services.

The objective of the majority of applications is closed logistics. The service robots for logistics can take over some of these tasks. The service robots for logistics are automated guided vehicles of smaller types. The units feature capacities lower than $250 \mathrm{~kg}$ and are designed for the transport of small objects or for lower loads in clean environment. Based on the method of movement, they are equipped by special devices, such as laser scanner, compartments for carrying post and similar compartments.

They act independently and they do not need any control. In medical institutions, the service robots are usually installed according to the point-by-point system. The characteristic transportation tasks include transport of meals, bedclothes, laboratory samples, and similar material to warehouses, and loading and unloading is performed by the personnel. The movement of robots is achieved by the usage of laser and scanning equipment, ultrasonic sensors and strategically located orientation sensors (often placed on the service robot ceilings).
The service robots have devices that allow them to communicate with automated doors and elevators in order to provide coverage of the entire building. More recently, there have been attempts for the robots to be able to collect goods from other mobile units, such as trailers, and to transport them between different stations located within the facility. In the future their use will be expanded thus insuring more efficient management of goods and reducing the influence of the ever increasing requirement for mobility.

To a small extent, logistic service robots will provide transportation service for hospitals, offices and public places. To a large extent, they represent an opportunity to increase the efficiency of using the routes through independent transportation of humans and goods. In both cases fast system management is necessary, which collects logistic requirements, dynamically assigns the routes and tasks for the robots, manages conflicts and incidents and plans preventive maintenance.

\section{DISTRIBUTION OF SERVICE ROBOTS FOR LOGISTCS}

According to the classification made and adopted by UNECE (United National Economic Commission for Europe) and IFR (International Federation of Robotics) the service robots have been divided into two groups: I personal/domestic service robots, and II - professional service robots. As mentioned, the International Federation of Robotics (IFR), the United Nations Economic Commission for Europe (UNECE) and the Organization for Economic Co-operation and Development (OECD) adopted the introductory system for the classification of service robots for logistics per categories and types of interactions, so that the service robots in logistics had the following classification.

\begin{tabular}{|l|l|}
\hline \multicolumn{2}{|c|}{ II - Professional service robots } \\
\hline $37-40$ & Logistic systems \\
\hline 37 & Courier systems - post \\
\hline 38 & Logistics in factories \\
\hline 39 & External and freight logictics \\
\hline 40 & Other logistics \\
\hline
\end{tabular}

Tab. 1. Classification of professional service robots for logistics [4]

Tab. 2 shows the statistical data collected by UNECE and International Federation of Robotics (IFR) from the manufacturers of service robots for logistics. 


\begin{tabular}{|l|l|l|l|l|l|}
\hline \multirow{2}{*}{$\begin{array}{l}\text { Application/ } \\
\text { year }\end{array}$} & \multicolumn{5}{|l|}{ Annual application of service robots } \\
\cline { 2 - 6 } & 2005 & 2007 & 2008 & 2009 & 2010 \\
\hline $\begin{array}{l}\text { Logictic } \\
\text { systems }\end{array}$ & 290 & 475 & 533 & 826 & 906 \\
\hline $\begin{array}{l}\text { Other } \\
\text { applications }\end{array}$ & 5,813 & 9,884 & 13,351 & 12,423 & 12,835 \\
\hline $\begin{array}{l}\text { TOTAL } \\
\sum\end{array}$ & 6,103 & 10,395 & 13,904 & 13,249 & 13,741 \\
\hline
\end{tabular}

Tab. 2. Annual application of service robots for logistics from 2005$2010[4,5]$

Based on Tab. 2 it can be concluded that from 2005 to 2010 there was an increase in the application of service robots for logistics. In 2005 the service robots in logistics accounted for $4.75 \%$ of the total number of service robots in that year, whereas in 2010 this percentage amounted to $6.6 \%$. This leads to the conclusion that the percentage of service robots for logistic systems is increasing from year to year in relation to the total number of the applications of service robots in one year for other fields.

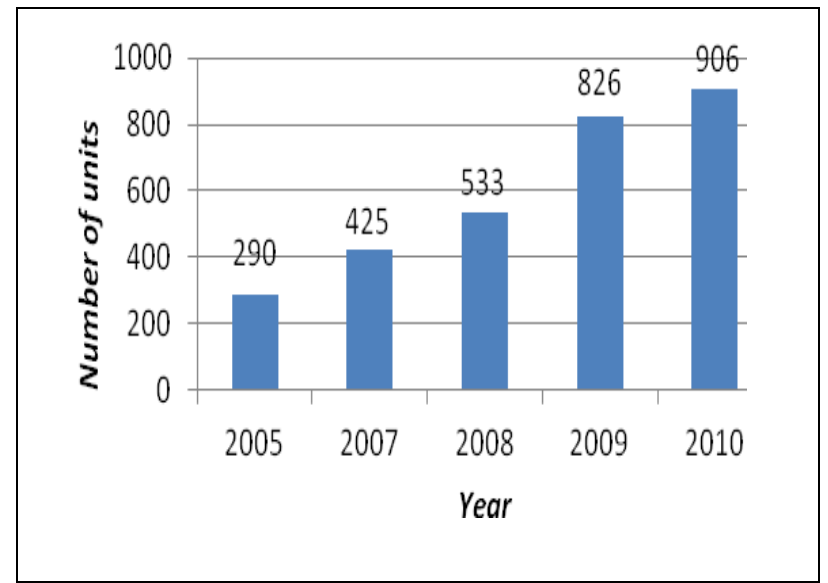

Fig. 2. Trend of service robots application in logistics from 2005-2010

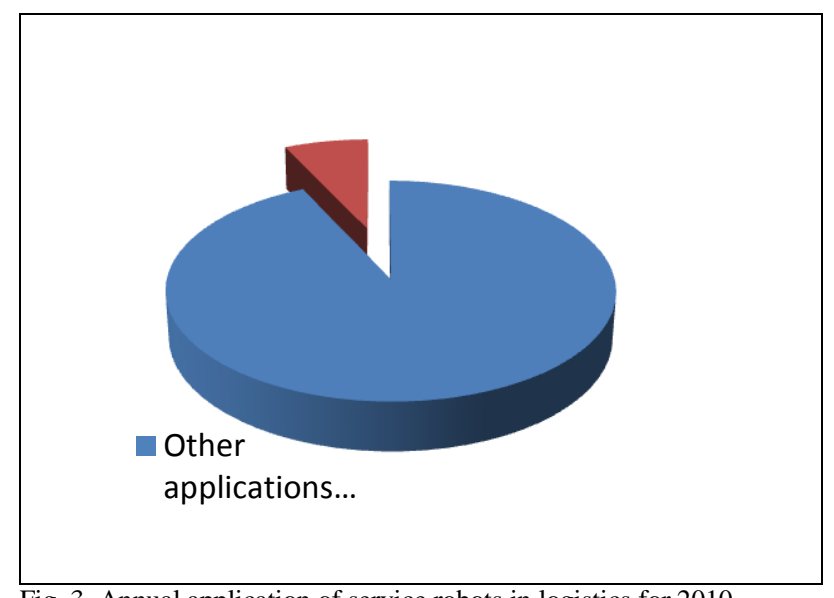

Fig. 3. Annual application of service robots in logistics for 2010

Fig. $\mathrm{s} 2$ and 3 show the trend of implementing service robots for logistic systems. As can be seen, the trend is increasing and in the last three years it can be said that there has been moderate increase in the implementation of service robots in this field. In 2010 out of the total number of implemented service robots about $7 \%$ were implemented for logistics in relation to the implementation of service robots for other fields.

The biggest relevant useful factors are: high quality of work and productivity, reduction of manual work, increased safety i.e. risk avoidance, increase of operative usability, temporary flexibility, new, pre-available contents, conditions, etc. Tab. 3 shows the estimate of relevance factor for the types of service robots that are implemented in logistics.

\begin{tabular}{|c|c|c|c|c|}
\hline $\begin{array}{l}37- \\
40\end{array}$ & $\begin{array}{l}\text { Logistic } \\
\text { systems }\end{array}$ & $\begin{array}{l}\text { High quality } \\
\text { of work } \\
\text { productivity }\end{array}$ & $\begin{array}{l}\text { Reduction } \\
\text { of manual } \\
\text { work }\end{array}$ & $\begin{array}{l}\text { Increase } \\
\text { of } \\
\text { operative } \\
\text { usability }\end{array}$ \\
\hline 37 & $\begin{array}{l}\text { Courier } \\
\text { systems - } \\
\text { post }\end{array}$ & & (R) & \\
\hline 38 & $\begin{array}{l}\text { Logistics in } \\
\text { factories }\end{array}$ & & $(\mathbb{R}(\mathbb{2}$ & \\
\hline 39 & $\begin{array}{l}\text { External } \\
\text { and freight } \\
\text { logistics }\end{array}$ & & ( & (R) \\
\hline
\end{tabular}

Tab. 3. Estimate of relevance factor for types of service robots in logistics

The Tab. shows the estimate of relevance factor for every type of service robot, with relevance level marked from 0 (not relevant) to two points (high relevance).

\section{SERVICE ROBOTS APPLICATION}

The service robots for logistics in hospitals are used to serve both the patients and the basic means that refer to the care and hygiene of the patients. These automated guided vehicles can unload and deliver cargo on the way between the given points. The vehicles (AGVs) Fig. 4 learn how to find their way along the main path between two locations, or they can be programmed to travel through complex hospital corridors, including also meeting with elevators, sliding doors and other devices. Another type of service robots used in hospitals is HELPMAT, promoted by the Minister of Health (USA).

The term originates from mid-1990s when a new term in the technology of autonomous mobile robots was used. There is a report that more than 100 units were installed by the year 2005. Helpmat transports meals for the patients, medicines to other departments, etc. This releases the professional staff from performing simple non-qualified courier tasks. The Intelligent TransCar LTC of Swisslog (Switzerland) collects large amounts of transport material of general use between the centralized functions, e.g. kitchen, laundry-room and lumber room. These automated guided vehicles (AGVs) learn to find their own way along the basic route between two places, or they can be programmed to travel through complex hospital corridors, including also connections with elevators, doors and other devices.

Service robots serving in offices, working premises and places where workers work with coffee and other services. The same robot can be used at hospitals where it is necessary to serve the patients, by bringing them medicine, water, tea, or whatever they might need.

At the beginning, AGVs relied on the prepared floors, such as embedded wire or magnets, for movement, guidelines. Still a significant amount in the system relies on cheap preparation of the environment, such as FLEXILANE, which moves along a tape embedded in 
the floor across which the transport and material lifting is performed, such as e.g. boxes, palettes, and other things that are placed into the container. In the meantime, free AGV navigation is used to the greatest extent for the logistics in production.

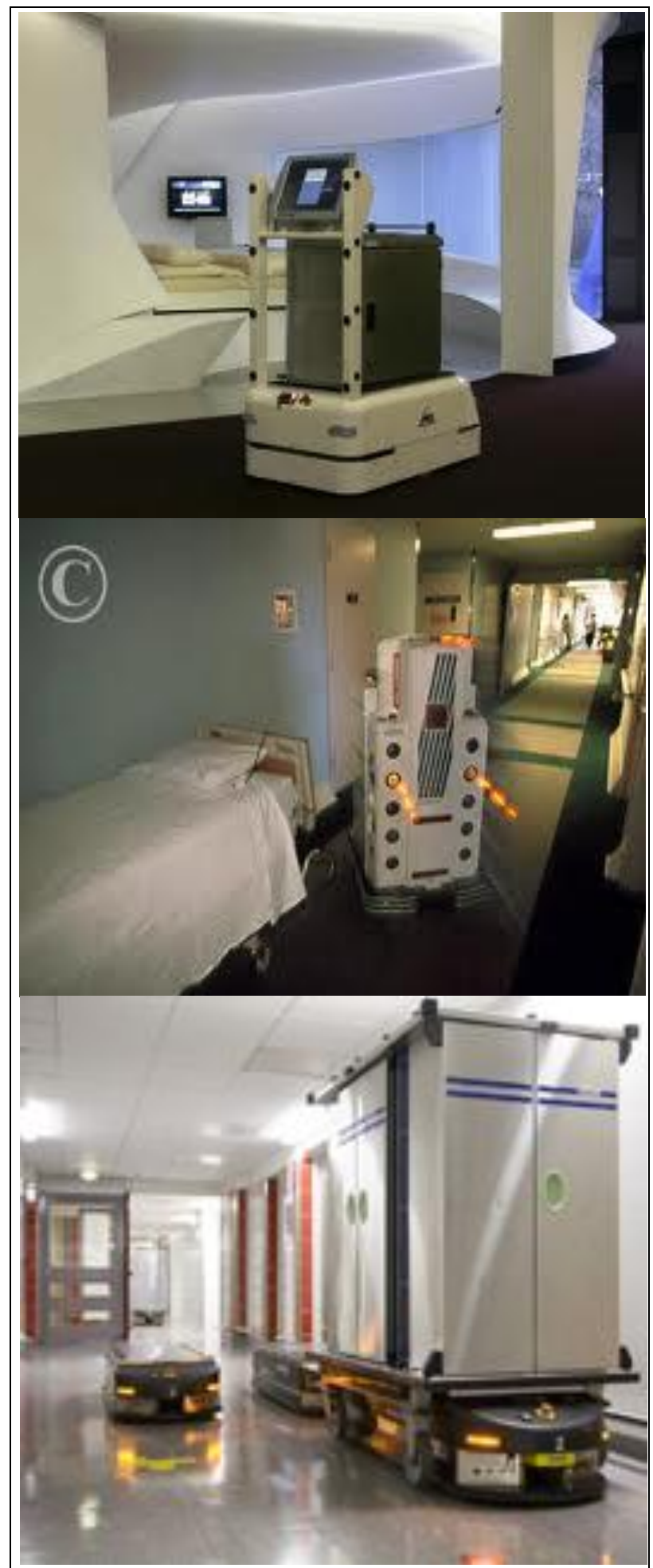

Fig. 4. Automated - AGV - vehicle for transport of materials in hospitals, Courier robot of type "Helpmat", TransCar LTC of Swisslog

Usually, their orientation is based on the laser scanners that provide accurate two-dimensional maps of the real surrounding, for self-localization and barrier avoidance. The solutions in mobile logistics represent the turning point in the operation and in the reduction of costs, thus making these devices profitable

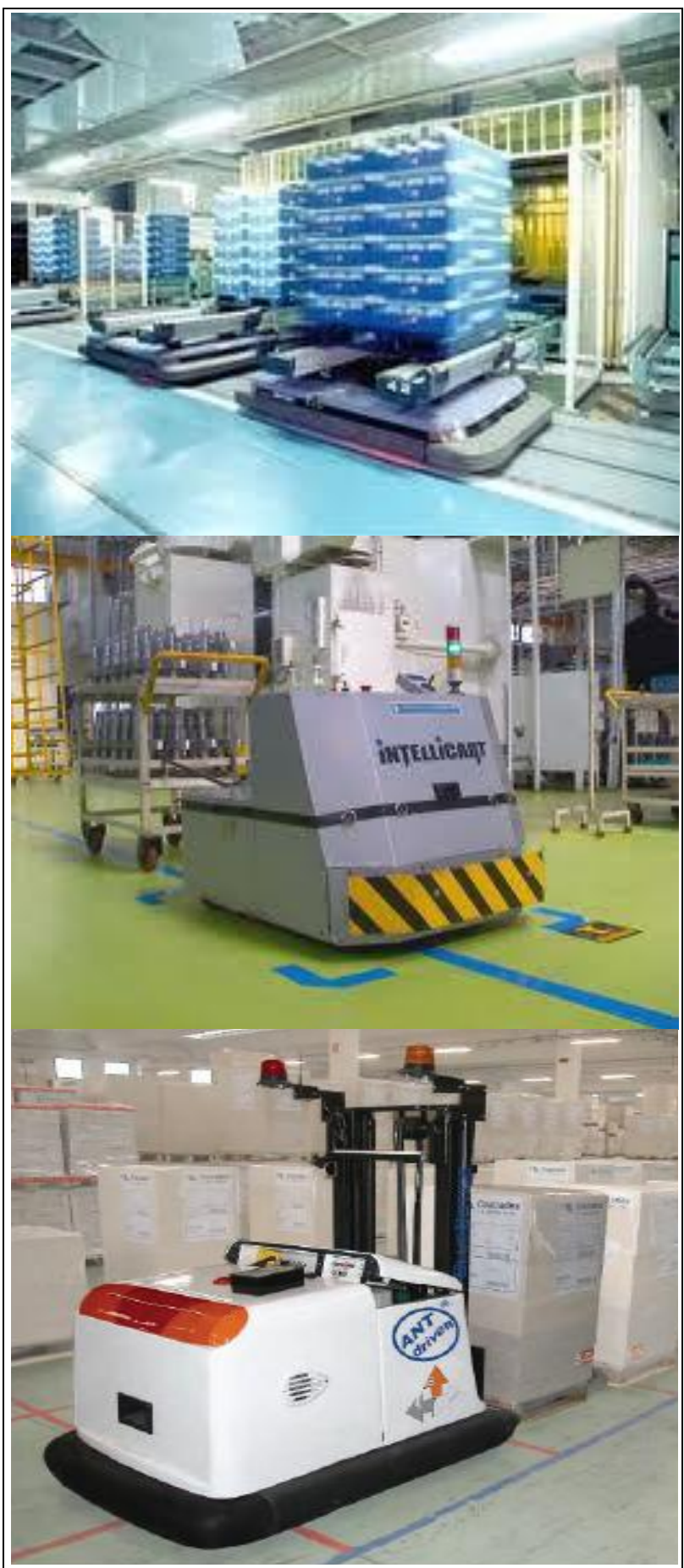

Fig. 5. Floor transport - "FLEXILANE"

The main benefit of robotic solutions in the introduction of logistic robots in factories is to reduce the need for manual workers, and especially drivers of trucks, forklifts, and the similar. AGVs rely on digital data to perform control and environmental protection, which in many cases, especially in small-size enterprises was hard to realize. Although AGVs in some cases do not reach the level predicted earlier, they can offer higher safety and they can be directed to some new and useful orientations, such as automatic unloading of the truck system. Many suppliers have started to solve the problem of minimizing the costs. There is attempt to reduce AGV 
costs in many ways such as e.g. by offering the possibility of leasing, or for the reduction of investments into the company without adding value to the processes such as logistics, and in such way as to reduce their dependence on the complex data for management processes. The main manufacturers of logistic system that refer to the factory logistics are: BA Systemes (France), BlueBotics (Switzerland), Euromaint (Sweden). Gottwald Port Technology (Germany), GPS / Neobotix (Germany), Inmach (Germany), Kiva (USA), Mobilrobot (USA), Robosoft (France).

\section{CONCLUSION}

The efficiency of logistic processes is important from the majority of aspects of our everyday lives. An example may be the problem of food availability in stores. The USA is currently importing more than 100,000 containers daily of the contents that have to be processed, distributed and made available to the customers. As technology, robotics has already been used for the automation in container handling in the ports of Australia and elsewhere, and it has the potential for improvement and increasing application in logistic systems. Food distribution from the farmers to the stores includes several phases of goods transport and handling. A significant part of the prices of foodstuffs is directly related to the logistic costs.

The next generation of robots, i.e. robotic technology has the potential to enable greater optimization of logistic processes and to reduce the price of food and other goods by several percent. In order to realize this, new technologies for the manipulation and handling of packages need to be provided. Transport, as a system, is wide and the implementation of robotics in this part of logistics as well is of extreme importance for sustainable development. This technology still has a high implementation price, but considering a longer period of time, the optimization of the logistic process and the reduction of the number of defects it results eventually in a cost-efficient investment. With greater implementation into various systems, the price of robotization should be lower as well.

\section{REFERENCES}

[1] Karabegović, I. Hodžić D, (2010), Application scenario of robot industry, CENT,M2- No.2. (ISSN 1986-5201), pp. 31-40

[2] Karabegović I., Doleček, V. (2003), The application of robots in the 21 century, 4th International Scientific Conference on Production Engineering RIM 2003, Bihać BiH, September 25th27th 2003, (ISBN 9958-624-16-8), pp. 3-22

[3] Karabegović, I., Karabegović, E., Mijović, B., Ujević,D.,(2010),Robots applied in medical institutions, 3. Međunarodni stručno-znanstveni skup, Zadar, 22-25 September, pp. 321-327

[4] World Robotics Service Robots 2010, United Nations, New York and Geneva, 2010

[5] World Robotics Service Robots 2008, United Nations, New York and Geneva, 2008

[6] World Robotics Service Robots 2006, United Nations, New York and Geneva, 2006

[7] Doleček, V., Karabegović, I. Robotika, Tehnički fakultet Bihać, Bihać, 2002
[8] Doleček, V., Karabegović, I. Roboti u industriji, Tehnički fakultet Bihać, Bihać, 2008

[9] *** (2012) http://www.worldrobotics.org/modules.php?nam $\mathrm{e}=$ News \&file $=$ article $\&$ sid $=3$

[10] *** (2012) http://www.ifr.org/news/ifr-press-release/ifr- roundTab.-on-the-future-of-robotics-153/

[11] *** (2012) http://robotland.blogspot.com/

[12] *** (2012) http://spectrum.ieee.org/blog/automaton?offset $=10 \& \max =10$

[13] $* * *$ (2012) http://robots.net/,

[14] $* * *$ (2012) http://www.androidworld.com/,

[15] $* * *$ (2012) http://slashdot.org/

[16] *** (2012) http://www.gorobotics.net/

[17] *** (2012) http://www.engadge t.com;

[18] *** (2012) http://www.robotcafe.com/

[19] *** (2012) http://www.therobotreport.com/ 